\title{
Investigation on the removal characteristics of single-point cutting high-volume fraction SiCp/Al composites
}

\section{Yongjie Bao}

Dalian Maritime University

\section{Xu Zhang}

Dalian University of Technology

Shouxiang Lu

Southern University of Science and Technology

Hongzhe Zhang ( $\square$ zhanghongzhe@dlut.edu.cn )

Dalian University of Technology

\section{Research Article}

Keywords: SiCp/Al composites, SiC particles, removal characteristics, finite element model, single grit cutting, Cutting mechanism, Metal matrix composite, Surface quality

Posted Date: April 1st, 2021

DOl: https://doi.org/10.21203/rs.3.rs-159623/v1

License: (9) This work is licensed under a Creative Commons Attribution 4.0 International License. Read Full License

Version of Record: A version of this preprint was published at The International Journal of Advanced Manufacturing Technology on September 9 th, 2021. See the published version at https://doi.org/10.1007/s00170-021-07977-5. 


\title{
Investigation on the removal characteristics of single-point cutting
}

\section{high-volume fraction $\mathrm{SiCp} / \mathrm{Al}$ composites}

\author{
Yongjie Bao ${ }^{1}$, Xu Zhang ${ }^{2}$, Shouxiang $\mathrm{Lu}^{3}$, Hongzhe Zhang ${ }^{2 *}$ \\ 1. Marine Engineering College, Dalian Maritime University, Dalian 116026, China \\ 2. Engineering Training Center, Dalian University of Technology, Dalian 116024, China \\ 3. Department of Mechanical and Energy Engineering, Southern University of Science and \\ Technology, Shenzhen 518055, China \\ *Corresponding author. E-mail address:zhanghongzhe@dlut.edu.cn (Hongzhe Zhang)
}

\begin{abstract}
SiC}$ reinforced aluminum matrix composites ( $\mathrm{SiCp} / \mathrm{Al}$ composites) are typical difficult-to-machine material, and the irregular $\mathrm{SiC}$ particles diffused in $\mathrm{SiCp} / \mathrm{Al}$ composites make the surface quality worse. In this paper, a single-point cutting investigations with finite element simulation were conducted for $65 \%$ $\mathrm{SiCp} / \mathrm{Al}$ composites and aluminum alloy. The surface morphology characteristics of $\mathrm{SiCp} / \mathrm{Al}$ composites, which mainly include breaking, part breaking, pulling out, protruding, al tearing, and interface debonding, are different from those of aluminum alloy materials. The high-volume $\mathrm{SiC}$ particles lower the surface quality and profile dimensional accuracy of $\mathrm{SiCp} / \mathrm{Al}$ composites. There are thin and discrete layers covered on the machined surface.
\end{abstract}

\section{Keywords:}

$\mathrm{SiCp} / \mathrm{Al}$ composites, $\mathrm{SiC}$ particles, removal characteristics, finite element model, single grit cutting, Cutting mechanism, Metal matrix composite, Surface quality

\section{Introduction}

$\mathrm{SiCp} / \mathrm{Al}$ composites with high $\mathrm{SiC}$ particles volume fraction have excellent physical and mechanical properties, including high specific strength, high specific modulus, good wear resistance, high temperature resistance, low thermal expansion coefficient and good dimensional stability [1-3]. SiCp/Al composites are widely used in aerospace industry, automotive industry, electronics industry and other fields [4-6]. However, due to clustering and non-homogeneous distribution of hard $\mathrm{SiC}$ particles in the ductile aluminum alloy matrix, $\mathrm{SiCp} / \mathrm{Al}$ composites have poor machinability. Both failure criteria and mechanical behaviors are different from homogeneous materials during the machining process. The material is a kind of typical difficult-to-machine material, which is easy to cause numerous surface defects and rapid tool wear rate in cutting process [7-11]. All of these make the machining of $\mathrm{SiCp} / \mathrm{Al}$ composites challenging. Therefore, the study on cutting characters of $\mathrm{SiCp} / \mathrm{Al}$ composites has become a hotspot.

At present, numerical modeling has been used by many researchers as a tool to understand the $\mathrm{SiCp} / \mathrm{Al}$ composites removal mechanisms associated with machining processes. Wang et al. [12] studied the influences of fracture and removal mechanism of $\mathrm{SiC}$ particles on surface generation using a three-dimensional (3D) finite element model of turning. It was found that the manners of $\mathrm{SiC}$ particulates removal have an important influence on surface generation. Liu et al. [13] and $\mathrm{Wu}$ et al. [14] using the finite element models studied the material removal mechanism and defect formation mechanism 
of $\mathrm{SiCp} / \mathrm{Al}$ composites considering tool and $\mathrm{SiC}$ particles interaction in different positions. The results showed that the major material removal form of $\mathrm{SiC}$ particles is brittle fracture and pulling out base on the different area of $\mathrm{SiC}$ particles in contacting with the tool. Xiang et al. [15] combined turning finite element analysis with ultrasonic assisted milling experiment and found that the application of ultrasound improved the particle rupture effect. An appropriate ultrasonic amplitude inhibited the particle breakage and slowed down the crack growth. A smoother particle breaking phenomenon was observed with the application of a higher frequency. Wang et al. [16] investigates the underlying cutting mechanism of $\mathrm{SiC}$ particle-reinforced aluminum matrix composites (MMCs) using finite element (FE) simulations and precision turning experiments. The results indicated that the particle size has significant influence on the surface quality of the machine surface of $\mathrm{SiCp} / \mathrm{Al} \mathrm{MMCs}$ and the fracture and removal of particle shows significant effect on the surface generation.

The single-point cutting test is an effective method to study the removal characteristics of particles reinforced metal matrix composites. Yan et al. [17] studied the cutting mechanisms and the relationship between specific energy of scratching and depth of cut (size effect) on low volume fraction (10\%-20\%) composites reinforced by $\mathrm{A}_{2} \mathrm{O}_{3}$ and $\mathrm{SiC}$ ceramic particles by single point cutting test. The results indicated that the scratch process was composed of rubbing, ploughing, plastic and for machining MMCs, a larger depth of cut should be used to maintain a lower machining energy, especially for those with a larger ratio of volume fraction to particle radius. Feng et al. [18] and Zha et al. [19] studied the scratch load, coefficient of friction (COF) and scratch morphology on $55 \%$ $\mathrm{SiCp} / \mathrm{Al}$ composites by comparing the ultrasonic vibration-assisted scratch (UVAS) and traditional scratch tests. The results indicated that the ultrasonic vibration played an important role in reducing the grinding force and $\mathrm{COF}$, as well as improving the morphology of the machined surfaces.

There is very little literature regarding the single-point cutting of higher volume fraction (greater than 55\%) SiCp/Al composites. The volume fraction increasing makes the cutting process more complicated. The material removal mechanism of high volume fraction $\mathrm{SiCp} / \mathrm{Al}$ composites still need further study. The material removal process is difficult to be directly observed due to the random distribution of different sized abrasive particles. Therefore, the single-point cutting test can be used to simplify the cutting process so that the material removal mechanism can be better revealed. And the finite element simulation can be used to reveal the material removal process in microscopic view and the elastic, plastic deformation and fracture process of $\mathrm{SiCp} / \mathrm{Al}$ composites can be revealed.

In this paper, the surface formation process of $65 \% \mathrm{SiCp} / \mathrm{Al}$ composites was studied. A single-point cutting investigations with finite element simulation were conducted. Compared with aluminum alloy, the cutting property and surface generation characteristics of $65 \% \mathrm{SiCp} / \mathrm{Al}$ composites were revealed.

\begin{tabular}{|llll|}
\hline Nomenclature & $\varepsilon_{f}$ & fracture strain \\
& & $\eta$ & stress triaxiality \\
$\sigma$ & flow stress (Mpa) & $p$ & pressure stress(Mpa) \\
$A$ & yield stress at reference & $q$ & von Mises equivalent stress (MPa) \\
\hline
\end{tabular}




\begin{tabular}{|c|c|c|c|}
\hline & temperature and strain rate $(\mathrm{Mpa})$ & & \\
\hline$B$ & strain hardening coefficient (Mpa) & $\varepsilon_{p}$ & plastic strain rate \\
\hline$\varepsilon$ & plastic strain & $\varepsilon_{0}$ & reference strain rate \\
\hline$n$ & the strain hardening exponent & $T_{\mathrm{r}}$ & $\begin{array}{l}\text { transition temperature defined as the } \\
\text { one at or below which there is no } \\
\text { temperature dependence on the } \\
\text { expression of the fracture strain }(\mathrm{K})\end{array}$ \\
\hline$m$ & thermal softening exponent & $\begin{array}{ll}\sigma_{1}, & \sigma_{2} \\
\sigma_{3}\end{array}$ & $\begin{array}{l}\text { principal stresses in three directions } \\
\text { respectively(Mpa) }\end{array}$ \\
\hline $\bar{\varepsilon}$ & strain rate & $\sigma_{\mathrm{p}}$ & tensile strength of material(Mpa) \\
\hline$\varepsilon_{0}$ & reference plastic strain rate & $\tau$ & friction force $(\mathrm{N})$ \\
\hline$T$ & workpiece temperature $(\mathrm{K})$ & $\mathrm{P}$ & positive pressure(Mpa) \\
\hline$T_{\mathrm{m}}$ & material melting temperature $(\mathrm{K})$ & $\sigma_{\mathrm{b}}$ & tensile strength of material \\
\hline$T_{\text {room }}$ & room temperature $(\mathrm{K})$ & $\mu_{\mathrm{n} 0}$ & normal displacement at failure \\
\hline$d_{1}-d_{5}$ & $\begin{array}{l}\text { Failure parameters of matrix } \\
\text { materials }\end{array}$ & $G_{f}^{\mathrm{I}}$ & mode I fracture energy \\
\hline$w_{\mathrm{D}}$ & scalar of failure state & $\sigma_{t u}^{\mathrm{I}}$ & failure stress \\
\hline$\Delta \varepsilon_{p}$ & $\begin{array}{l}\text { equivalent plastic strain during } \\
\text { each integration cycle }\end{array}$ & $G_{\mathrm{s}}$ & shear modulus after the crack opening \\
\hline$\mu$ & coefficient of sliding friction & $G$ & $\begin{array}{l}\text { shear modulus of the undamaged } \\
\text { material }\end{array}$ \\
\hline$\rho\left(e_{n n}^{c k}\right)$ & shear retention factor of material & $e_{n n}^{c k}$ & cracking opening strain \\
\hline & material parameters & $e_{\max }{ }^{c k}$ & material parameters \\
\hline
\end{tabular}

\section{$2 \mathrm{SiCp} / \mathrm{Al}$ composites removal model}

2.1 Finite element model

A microstructure-based two-dimensional plane strain and random particle single point cutting model was built with Abaqus/Explicit by imitating the real particle morphology from typical micrographs of $65 \% \mathrm{SiCp} / \mathrm{Al}$ composites, as shown in the upper half of Fig. 1. In this model, the volume fraction of $\mathrm{SiC}$ particle in $\mathrm{SiCp} / \mathrm{Al}$ composites is $65 \%$ and the $\mathrm{SiC}$ particles exhibited an average size of about $40 \mu \mathrm{m}$. The workpiece length and height are $1.6 \mathrm{~mm}$ and $0.4 \mathrm{~mm}$. The cone vertex angle and radius of the single diamond grit is $120^{\circ}$ and $0.2 \mathrm{~mm}$ respectively. The cutting speed is $5.26 \mathrm{~m} / \mathrm{s}$, and the cutting path is circular arc. The maximum cutting depth 20 $\mu \mathrm{m}$ is available in the bottom of the circular arc. It can also be seen that the morphology of the $\mathrm{SiC}$ particles, which agrees with typical micrographs of $65 \% \mathrm{SiCp} / \mathrm{Al}$ composites, is polygonal, including quadrilateral, pentagon and hexagon. In order to simplify the algorithm, the volume fraction is defined as the ratio of sum of polygon areas and workpiece area. The model of the workpiece is generated by a custom subroutine which can automatically build model of workpiece by setting some model parameters, such as sic particles shape, diameter and volume fraction. The custom subroutine also enables random distribution of particles in the matrix. In the simulation, the random distribution of particles can truly reproduce the microstructure of the composite; the interaction between particles can also be fully considered [20]. In this model, the matrix and the particles were modeled separately and the 4-node plane strain bilinear quadrilateral elements (CPE4RT) in ABAQUS were 
adopted to mesh both the matrix and $\mathrm{SiC}$ particles. The global element size of 0.0055 $\mathrm{mm}$ was selected. Since the interface is very hard and brittle and hence similar to the particles [21], the interface was considered as an extension of the particle. The particle and the matrix are tied together so that their initial displacements at the interface are equal. The interfacial debonding is achieved through the failure of the matrix material which is also used by other researchers [22-25].

The tool used in this experiment is a standard diamond indenter, and it is simplified in the simulation. Because the tool has the characteristics of high hardness, strength, wear resistance, and high temperature resistance, less deformation occurred during machining process. It is established to the rigid body, to improve the calculation efficiency. And the reference point is set on the tool to control the tool cutting path and output the cutting force and other parameters.
Penalty contact between the cutting tool with matrix and particles is defined with the aim of enabling the tool-particle interaction. The workpiece is constrained at bottom and sides surface. Furthermore, a two-dimensional plane strain model of aluminum alloy (0 vol \%) was also built to compare with the $\mathrm{SiCp} / \mathrm{Al}$ composites (65 vol \%), as shown in the bottom half of Fig. 1. The main difference between the model of $2 \mathrm{a} 12$ aluminum alloy and $\mathrm{SiCp} / \mathrm{Al}$ composites is whether the workpiece contains sic particles or not. Through comparative analyses of material removal processes, the influence of $\mathrm{SiC}$ particles on surface generation of $\mathrm{SiCp} / \mathrm{Al}$ composites can be revealed.

In this work, the single point geometric parameters, cutting path, maximum cutting depth, cutting speed, average particle size, volume fraction and so on are all comparable to the experimental data.

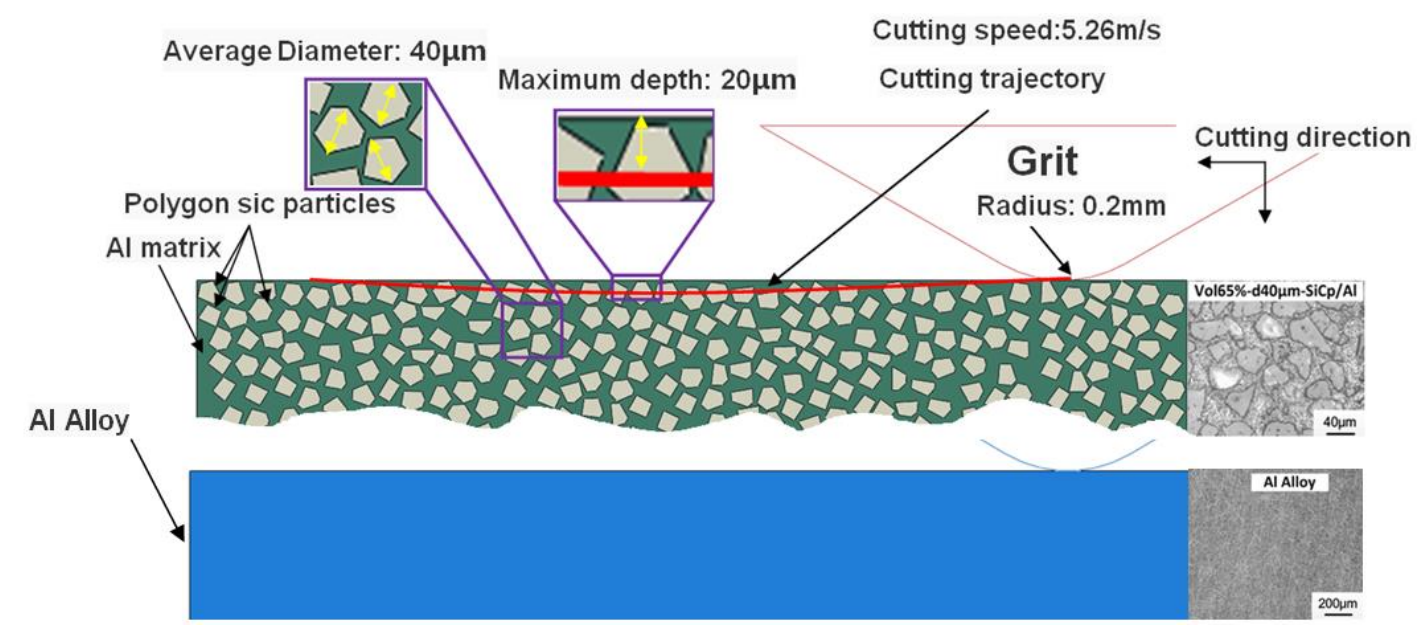

Fig. 1 Finite element model of single point cutting of $65 \% \mathrm{SiCp} / \mathrm{Al}$ composites and 2A12 aluminum alloy

\subsection{Material constitutive equation}

Aluminum alloy has flow characteristics and is greatly influenced by strain, strain rate and high temperature. Johnson-Cook constitutive equation includes those influence factors. Thus, it can well simulate the cutting process of matrix materials in practice. In this work, the Johnson-Cook constitutive equation was implemented to model the flow behavior of $\mathrm{Al}$ alloy. Here, the Johnson-Cook model can be expressed as:

$$
\sigma=\left[A+B \varepsilon^{\mathrm{n}}\right]\left[1+C \ln \left(\frac{\bar{\varepsilon}}{\varepsilon_{0}}\right)\right]\left[1-\left(\frac{T-T_{r}}{T_{m}-T_{r}}\right)^{m}\right]
$$


Where $\sigma$ is the flow stress, $A$ is the yield stress at reference temperature and strain rate, $B$ is the strain hardening coefficient, $\varepsilon$ is the plastic strain, $n$ is the strain hardening exponent, $C$ is the strain rate sensitivity coefficient, and $m$ is the thermal softening exponent, $\bar{\varepsilon}$ is the strain rate, $\varepsilon_{0}$ is the reference plastic strain rate. $T$ is the workpiece temperature, and $T_{\mathrm{m}}$ and $T_{\mathrm{r}}$ are the material melting and room temperature, respectively.

The material constants of 2A12 Al alloy matrix are obtained from the split Hopkinson pressure bar (SHPB) test over wide temperatures and strain rates by $\mathrm{Li}$ [26] and listed in Table 1. The material parameters of $\mathrm{Al}$ alloy matrix and silicon carbide applied in the finite element computational analysis are listed in Table 2 [26-28].

Table 1 Material constants for Johnson-Cook constitutive model of 2A12 $\mathrm{Al}$ alloy

\begin{tabular}{cccccc}
\hline$A / \mathrm{MPa}$ & $B / \mathrm{MPa}$ & $n$ & $C$ & $m$ & $T_{\text {melt }} / \mathrm{K}$ \\
\hline 370.4 & 1798.7 & 0.73315 & 0.0128 & 1.5282 & 863 \\
\hline
\end{tabular}

Table 2 Material parameters of $2 \mathrm{~A} 12 \mathrm{Al}$ alloy and $\mathrm{SiC}$

\begin{tabular}{ccc}
\hline Material parameters & $2 \mathrm{~A} 12$ & $\mathrm{SiC}$ \\
\hline$E$, Young's modulus $(\mathrm{GPa})$ & 71.7 & 420 \\
$\mu$, Poisson's ratio $\mu$ & 0.33 & 0.14 \\
Coefficient of thermal expansion $\left(\mathrm{K}^{-1}\right)$ & $26.6 \times 10^{-6}$ & $4.9 \times 10^{-6}$ \\
$\rho$, Density $\left(\mathrm{kg} \cdot \mathrm{m}^{-1}\right)$ & $2.77 \times 10^{3}$ & $3.13 \times 10^{3}$ \\
$k$, Thermal conductivity $/\left(\mathrm{W} \cdot \mathrm{m}^{-1} \cdot \mathrm{K}^{-1}\right)$ & 175 & 81 \\
$C$, specific heat $\mathrm{C} /\left(\mathrm{J} \cdot \mathrm{kg}^{-1} \cdot \mathrm{K}^{-1}\right)$ & 921 & 427 \\
\hline
\end{tabular}

\subsection{Fracture criterion of matrix material}

Liu.et all [29] found that the simulation results agreed well to the experiment results of metal cutting process when using the Johnson-Cook damage criterion including failure evolution model. Thus, in this work, Johnson-Cook damage criterion was utilized to describe the chip separation behavior for all the Al alloy matrix elements. Johnson-Cook criterion for damage initiation is met when the following condition is satisfied [30]:

$$
w_{D}=\sum \frac{\Delta \varepsilon^{p}}{\varepsilon_{f}}=1
$$

$\varepsilon_{f}=\left[d_{1}+d_{2} \exp \left(-d_{3} \eta\right)\right]\left[1+\ln \left(\frac{\varepsilon^{p}}{\varepsilon_{0}}\right)\right]\left[1+d_{5}\left(\frac{T-T_{r}}{T_{m}-T_{r}}\right)\right]$

Here, $w_{\mathrm{D}}$ is scalar of failure state, $\Delta \varepsilon^{\mathrm{p}}$ is the change in the equivalent plastic strain during each integration cycle, $\varepsilon_{f}$ is the fracture strain, $d_{1}-d_{5}$ are the failure parameters of matrix materials, $\eta=p / q$ is the stress triaxiality, $p$ is the pressure stress, $q$ is the von Mises equivalent stress, $\varepsilon^{\mathrm{p}}$ and $\varepsilon_{0}$ are the plastic strain rate and reference strain rate respectively. $T$ and $T_{\mathrm{m}}$ are the workpiece temperature and melting temperature, and $T_{\mathrm{r}}$ is the transition temperature defined as the one at or below which there is no temperature dependence on the expression of the fracture strain $\varepsilon_{f}$ [30]. In addition, the $\mathrm{SiC}$ particles are modeled as an isotropic and perfectly elastic material following the generalized Hook's Law, and brittle cracking model was used. The failure parameters $\mathrm{d} 1-\mathrm{d} 5$ applied in the Abaqus/Explicit are listed in Table 3 [28]. 
Table 3 Johnson-Cook damage parameters of 2A12 Al alloy matrix

\begin{tabular}{ccccc}
\hline $\mathrm{d} 1$ & $\mathrm{~d} 2$ & $\mathrm{~d} 3$ & $\mathrm{~d} 4$ & $\mathrm{~d} 5$ \\
\hline 0.116 & 0.211 & -2.172 & 0.012 & -0.01256 \\
\hline
\end{tabular}

\subsection{Fracture criterion of $\mathrm{SiC}$ material}

In this paper, the brittle fracture criterion was added into the material property of SiC to simulate the cracking of $\mathrm{SiC}$ particles in cutting process. SiC particles are hard and in elastic state before fracture, and he relationship of stress and strain obeys the generalized Hook's law. The judgement of fracture initiation is maximum normal stress criterion [31]. The formula can be expressed as:

$$
\max \left(\sigma_{1}, \sigma_{2}, \sigma_{3}\right)=\sigma_{b}
$$

Here, $\sigma_{1}, \sigma_{2}$ and $\sigma_{3}$ are principal stresses in three directions respectively. $\sigma_{\mathrm{b}}$ is tensile strength of material. The crack is assumed to initiate if the $\max \left(\sigma_{1}, \sigma_{2}, \sigma_{3}\right)$ is greater than or equal to $\sigma_{\mathrm{b}}$.

After the initiation of crack, fracture energy criterion is used to control the degradation of tension stiffening, and the crack normal displacement at failure is defined as [31]:

$$
\mu_{\mathrm{n} 0}=2 G_{f}^{\mathrm{I}} / \sigma_{t u}^{\mathrm{I}}
$$

Here, $\mu_{\mathrm{n} 0}$ is the normal displacement at failure, $G_{f}^{\mathrm{I}}$ is the mode I fracture energy, and $\sigma_{t u}{ }^{\mathrm{I}}$ is the failure stress.

A function of the crack opening strain about the shear retention model is defined to describe the damage development of sic particle caused by shear stress. The shear modulus after the crack opening is $G_{\mathrm{s}}$ and it can be calculated by the following formula [31]:

$$
G_{\mathrm{s}}=\rho\left(\mathrm{e}_{n n}^{c k}\right) G
$$

Here, $G$ is the shear modulus of the undamaged material, and $\rho\left(\mathrm{e}_{\mathrm{nn}}{ }^{\mathrm{ck}}\right)$ is the shear retention factor of material, which can be calculated by the following formula [31]:

$\rho\left(\mathrm{e}_{n n}^{c k}\right)=\left(1-\frac{e_{n n}^{c k}}{e_{\max }^{c k}}\right)^{p}$

Here, $\mathrm{e}_{\mathrm{nn}}{ }^{\mathrm{ck}}$ is the cracking opening strain; $p$ and $e_{\max }{ }^{\mathrm{ck}}$ are material parameters [32]. The parameters about the material fracture model are listed in Table 4 [33].

Table 4 Parameters of the material fracture model

\begin{tabular}{cccc}
\hline$\sigma_{\mathrm{b}}(\mathrm{Mpa})$ & $G_{f}^{\mathrm{I}}\left(\mathrm{J} / \mathrm{m}^{2}\right)$ & $p$ & $e_{\max }{ }^{\mathrm{ck}}$ \\
\hline 1500 & 30 & 1 & 0.001 \\
\hline
\end{tabular}

\subsection{Friction model}

The friction between the tool and the workpiece has great effect on cutting force and cutting temperature, thus affecting the surface integrity. Therefore, the selection of friction model is very important for guaranteeing a high-quality calculation. The chip of high-volume fraction $\mathrm{SiCp} / \mathrm{Al}$ composites has high brittleness, and the tool-chip relative sliding is more remarkable than tool-chip coalescence. Therefore, coulomb friction model is applied into the interaction between the tool and the matrix material as well as the tool and SiC particles. The formula can be expressed as:

$\tau=\mu \mathrm{P}$

Here, $\tau$ is friction force, $\mu$ is coefficient of sliding friction and $P$ is positive pressure. A constant Coulomb friction coefficient of 
$\mu=0.5$ is used in all simulations since it represents sliding contact condition between the tool and the workpiece [34].

2.6 Simulation results of single point cutting

Aluminum alloy has good plasticity and low hardness while $\mathrm{SiC}$ is hard and brittle. $\mathrm{SiCp} / \mathrm{Al}$ composites contain both aluminum alloy and $\mathrm{SiC}$ particles, which makes the cutting process complex. Especially for high-volume fraction $\mathrm{SiCp} / \mathrm{Al}$ composites, the cutting characteristics needs to be further revealed. Thus, single point cutting simulation was carried out on the three materials for revealing the influence of volume fraction on cutting quality through comparative analyses.

Fig. 2 shows the surface topography of aluminum alloy after single point cutting simulation. It can be seen that aluminum alloy has good surface integrity and no defects like pits or cracks after cutting. Furthermore, there is only plastic deformation and few scales, and the fluctuation of the contour is small.

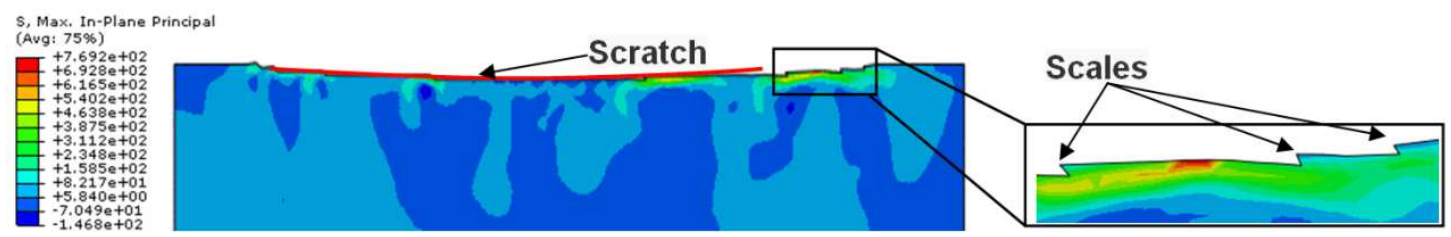

Fig. 2 Removal models of 2A12 aluminum alloy materials

Fig. 3 shows the surface topography of $65 \% \mathrm{SiCp} / \mathrm{Al}$ composites. It can be found that the high-volume fraction of $\mathrm{SiC}$ particles increase the brittleness of material and the material surface has defects like interfacial debonding (Fig. 3a), protruding(Fig. 3b), pulling out(Fig. 3c), crushing(Fig. 3d), part crushing(Fig. 3f), al tearing(Fig. 3e) and so on. As a whole, the cutting surface presents an uneven surface topography including pits, protruding and plastic deformation, severely affecting the surface quality. The cutting surface of $\mathrm{SiCp} / \mathrm{Al}$ composites is very different from aluminum alloy. The addition of $\mathrm{SiC}$ particles changes the materials removal mechanism. There are both plastic failure of aluminum matrix and brittle failure of $\mathrm{SiC}$ particles in the failure procedures of $\mathrm{SiCp} / \mathrm{Al}$ composites. Furthermore, because of the high hardness of $\mathrm{SiC}$ particles, it generates pushing effect on aluminum alloy, causing the appearance of micro-cracks and deformation on the surface topography.

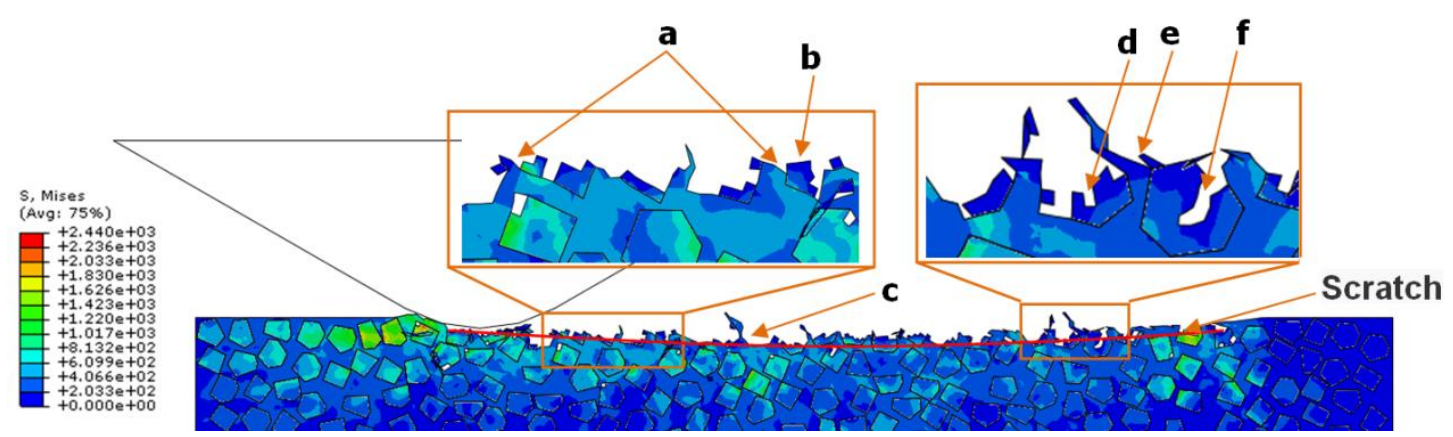

Fig. 3 Removal models of $65 \% \mathrm{SiCp} / \mathrm{Al}$ composites

3 Single point cutting experiment

In order to reveal the material removal characteristics, single point cutting experiments were carried out on aluminum 
alloy and $65 \% \mathrm{SiCp} / \mathrm{Al}$ composites. The scratch appearance and micro morphology were observed, and the characteristics of material failure were analyzed.

\subsection{Pretreatment of materials}

The materials used in the experiments were $2 \mathrm{~A} 12$ aluminum alloy and $65 \% \mathrm{SiCp} / \mathrm{Al}$ composites. The mean diameter of the $\mathrm{SiC}$ particles is $40 \mathrm{um}$. In order to reduce the effects of surface roughness and residual stress on experimental results, rotation and gravity type of grinding-and-polishing machine was utilized to grind and polish the materials. The average roughness of all test workpieces is less than $0.05 \mu \mathrm{m}$ after the pretreatment and the surface topography pictures were shown in Fig. 4.

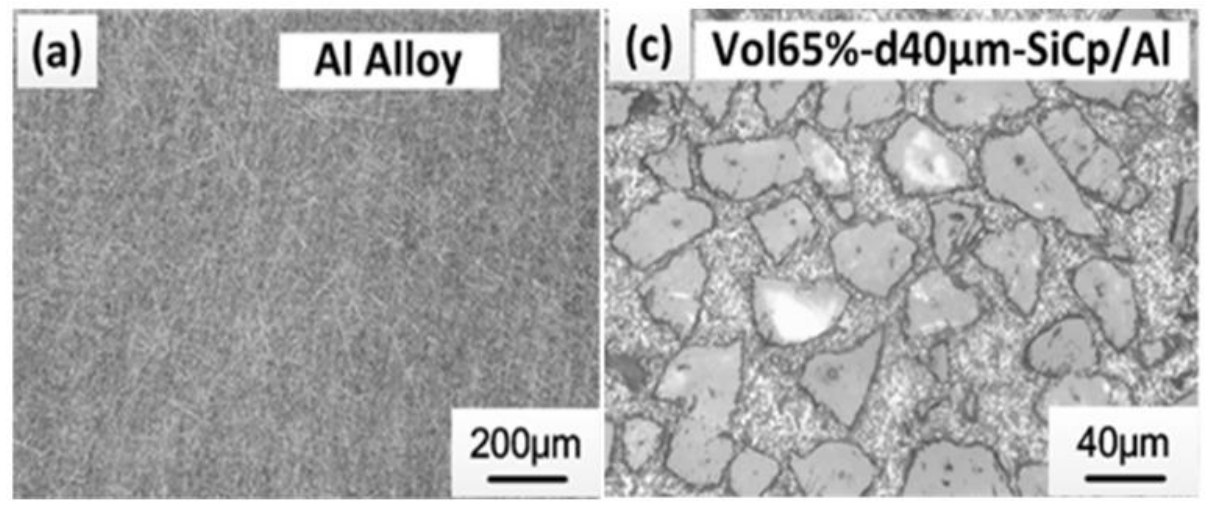

Fig. 4 Surface topography of test pieces after pretreatment

\subsection{Experimental details}

The experiments were carried out on CNC drilling and milling test bench, and the testing apparatus is shown in Fig. 5.

It can be seen that the disc-like aluminum alloy cutterhead is clamped in the end of motorized spindle. The rockwell hardness indenter is fixed on the columned clamp holder and is connected with aluminum alloy cutterhead through screw threads. In the experimental speed range, in order to make the tool and the fixture in a dynamic balancing state, a clump weight is installed on the columned clamp holder symmetrically to the aluminum alloy cutterhead. Workholder is fixed on the Kistler 9257b three-component dynamometer and the latter is fixed on the machine table, linking with computer through charge amplifier and data acquisition card.

During experiments, the machine spindle rotates and the rotating speed is $\mathrm{n}$. In order to ensure that the scratch on the test specimen is only through one cutting, the relative motion between the test specimen and the tool should be reasonably controlled. The machine tool feed movement process undergoes acceleration and uniform motion stage successively. The acceleration time or deceleration time of the feed movement of the tool is $0.1 \mathrm{~s}$, and the acceleration distance or deceleration distance is $5 \mathrm{~mm}$. Thus, the distance between the diamond grit tip of rockwell hardness indenter and test specimen is $5 \mathrm{~mm}$ after tool setting, as shown in Fig. 6. The cutting depth is set as $h$. The machine spindle moves to a specified position at a speed of $v_{f}$ and stops for holding $\Delta t$ seconds, and then moves back to the initial point at a speed of $-v_{f}$. In addition, the holding time is crucial, because if the $\Delta t$ is too large, the frequency of exposure between the tool and the test specimen will be more than once. While, if the $\Delta t$ is too small, the tool will not be in contact with the test specimen. Thus, $\Delta t$ 
should be determined appropriately under the corresponding spindle speed, ensuring the frequency of exposure between tool and test specimen to be only once. In order to investigate the detailed interface profile and surface morphology, KEYENCE VK-X250 laser scanning confocal microscope (LSCM) and FEIQ45 scanning electron microscope (SEM) were used to examine the surface of the samples. The parameters of single point dicing are shown in Table 5.

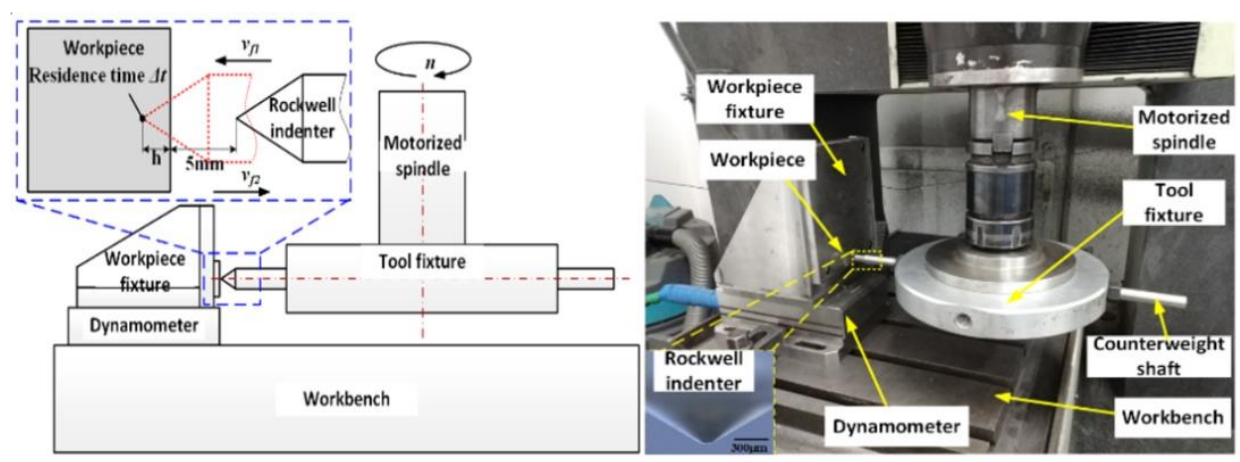

Fig. 5 The method of dicing test and testing apparatus

Table 5 The parameters of single point dicing

\begin{tabular}{cccccc}
\hline $\begin{array}{c}\text { Cutting depth } \\
\mathrm{h} / \mu \mathrm{m}\end{array}$ & $\begin{array}{c}\text { Cutting radius } \\
\mathrm{r} / \mathrm{mm}\end{array}$ & $\begin{array}{r}\text { Cutting speed } \\
/\left(\mathrm{m}^{\mathrm{s}} \mathrm{s}^{-1}\right)\end{array}$ & $\begin{array}{c}\mathrm{V}_{\mathrm{s}} \\
\text { 20 }\end{array}$ & $\begin{array}{c}\text { Holding time } \\
\Delta \mathrm{t} / \mathrm{s}\end{array}$ & $\begin{array}{c}\text { Feed speed } \\
\mathrm{V}_{\mathrm{f}} /\left(\mathrm{mm} \cdot \mathrm{min}^{-1}\right)\end{array}$ \\
\hline
\end{tabular}

\section{Experimental results and discussions}

\subsection{Cutting force}

In order to validate this model, a comparison was made between the simulated and experimental measurements of the cutting force. The maximum, minimum and average values of cutting force were calculated from the data based on the simulation and experiment, as shown in Table 6. The average cutting force error of $\mathrm{Al}$ alloy and $\mathrm{SiCp} / \mathrm{Al}$ is $8.67 \%$ and $8.06 \%$ respectively. By calculating the average cutting force error of simulation and experiment, which is also used by Zhou et al. [34], can prove that simulation model is reasonable.

Table 6 Material parameters of $2 \mathrm{~A} 12 \mathrm{Al}$ alloy and $\mathrm{SiC}$

\begin{tabular}{ccccc}
\hline Cutting force & Maximum(N) & Minimum(N) & Average $(\mathrm{N})$ & Average error $(\%)$ \\
\hline Al alloy(simulation) & 20.6244 & 2.3504 & 12.2999 & 8.67 \\
Al alloy(experiment) & 18.7298 & 0.5215 & 11.3194 & \\
SiCp/Al(simulation) & 32.1861 & 1.18098 & 15.1241 & 8.06 \\
SiCp/Al(experiment) & 23.9737 & 0.2536 & 13.9960 & \\
\hline
\end{tabular}

\subsection{Overall surface topography}

The overall surface topography of the three materials is shown in Fig. 6. It can be seen that the scratch appearance of aluminum alloy is clear. Material accumulation appeared on both sides of scratch centerline showing plastic flow features. In the case of $65 \%$ $\mathrm{SiCp} / \mathrm{Al}$ composites, material accumulation also occurs on both sides of scratch centerline. However, the centerline is poor than 
aluminum alloy, and the accumulation of materials is discontinuous, having low surface flatness. The overall surface topography of the two materials matches the simulation well. Aluminum alloy has good plastic-flow features, and there are common phenomena in metal cutting process, such as scraping, ploughing and cutting. In the case of $65 \%$
$\mathrm{SiCp} / \mathrm{Al}$ composites, although the aluminum matrix still has plasticity features, the addition of $\mathrm{SiC}$ particles increases the brittleness of $\mathrm{SiCp} / \mathrm{Al}$ composites and causes the low surface flatness. It can be seen that the increase of volume fraction of $\mathrm{SiC}$ particles will decrease the surface quality of cutting.

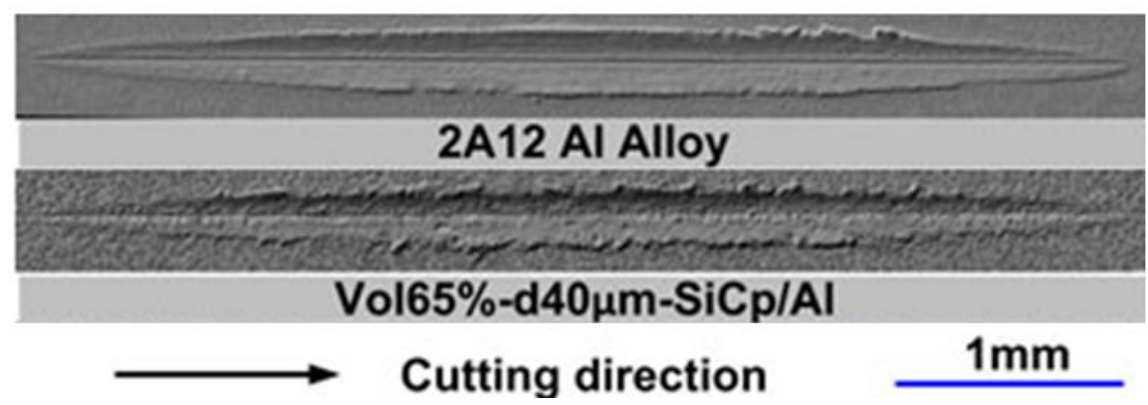

Fig. 6 The overall appearance of three materials after dicing

\subsection{Morphology of longitudinal cross-section}

The scratch profile curves of the two materials were measured by confocal laser scanning microscope. The profile variation is shown in Fig. 7a. Part 'b', 'c' and 'd' marked in Fig. 7a, correspond to the cut-in parts (Fig. 7b), maximum cutting depth parts (Fig. 7c) and cut-out parts (Fig. 7d). Fig. 7b, c and d are partially enlarged part of the Fig. 7a. It can be seen that the scratch profile curve of aluminum alloy is most similar to the nominal profile curve among the two materials. The profile integrity is good and the profile fluctuation is small. However, the scratch profile curve of $65 \% \mathrm{SiCp} / \mathrm{Al}$ composites obviously deviates from the nominal profile curve and the range of profile variation is obviously wider than aluminum alloy. It shows that the addition of $\mathrm{SiC}$ particles increases the brittleness of $\mathrm{SiCp} / \mathrm{Al}$ composites and the brittle fracture causes the remarkable profile fluctuation. Thus, the profile integrity of $65 \% \mathrm{SiCp} / \mathrm{Al}$ composites is worse than aluminum alloy as well.

From further analyses of cut-in parts
(Fig. 7b), maximum cutting depth parts (Fig. 7c) and cut-out parts (Fig. 7d), it can be seen that, in the initial cut-in stages, the plastic deformation of aluminum alloy occurred under the action of tool, and the profile dimension is similar to nominal profile dimension. Since the $\mathrm{SiC}$ particles increase the hardness of $\mathrm{SiCp} / \mathrm{Al}$ composites, the amount of deformation in the initial stage is small and the fluctuation of deformation increases with the deepening of the tool. It can be seen that From the Fig. 7, the profile fluctuation range of aluminum alloy is about $3 \mu \mathrm{m}$, but the profile fluctuation range of $\mathrm{SiCp} / \mathrm{Al}$ composites, which is almost 3 times of the aluminum alloy, is about $8 \mu \mathrm{m}$. In maximum cutting depth parts (Fig. 7c), the profile curve of aluminum alloy is almost as same as the nominal profile curve and the profile fluctuation is very small, the profile fluctuation range reaching its minimum. However, the profile fluctuation of $\mathrm{SiCp} / \mathrm{Al}$ composites is big and the profile fluctuation range reaches its maximum. The reason for the phenomenon is that, at maximum cutting 
depth part, in the process of cutting, plastic deformation was mainly undergone in aluminum alloy, but brittle fractures was mainly undergone in $\mathrm{SiCp} / \mathrm{Al}$ composites.

From the longitudinal section morphology of the scratch, it can be seen that
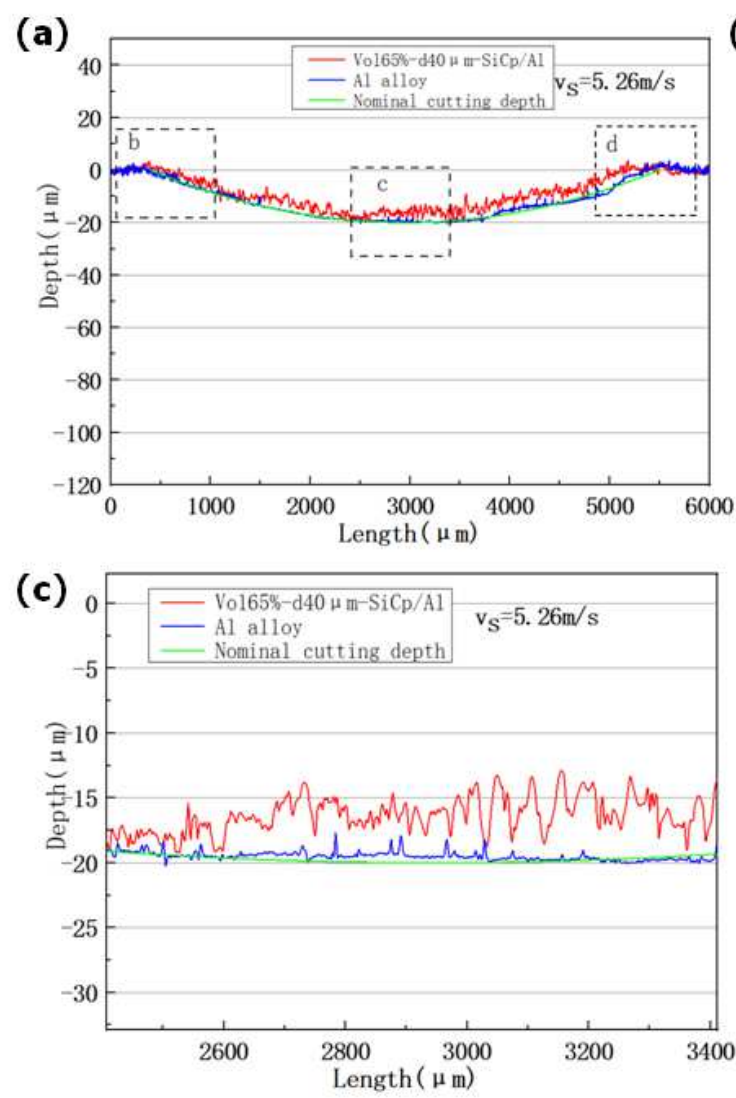

the fluctuation of profile curve of the $\mathrm{SiCp} / \mathrm{Al}$ composites increases with the addition of $\mathrm{SiC}$ particles. The cutting quality of $\mathrm{SiCp} / \mathrm{Al}$ composites is obviously lower than aluminum alloy, indicating that the simulated analysis matches the test well.

Fig. 7 The scratch profile dimensions of three materials after dicing

\subsection{Scratch morphology}

The surface topography of the three kinds of cut specimens was examined to reveal the removal characteristics of $\mathrm{SiCp} / \mathrm{Al}$ composites by comparative analyses.

The results of cutting simulations are compared to single point cutting experimental results, as shown in Fig. $8 \mathbf{a}$ and b. It can be seen that except for plastic deformation, some scales were found on the surface of $2 \mathrm{~A} 12 \mathrm{Al}$. The reason for the generation of scales is considered that the tension stress in the cutting process may induce crack growth and so scales damage appear on the surface of (b)

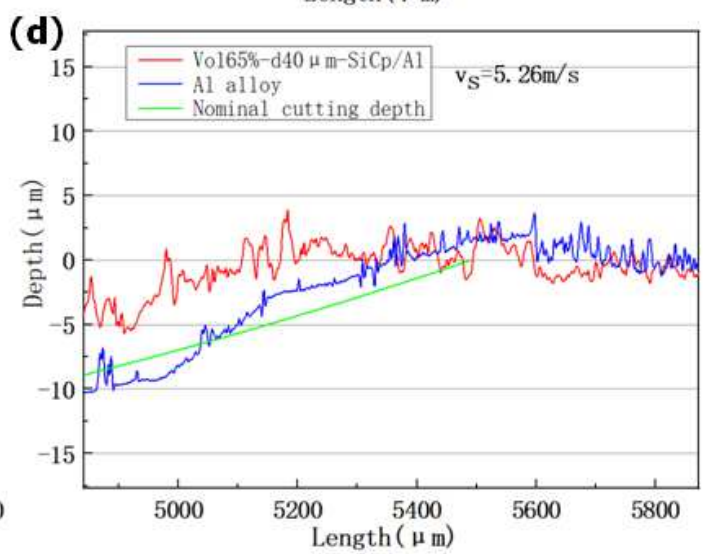


phenomenon on the surface of $\mathrm{SiC}$ particles and make the aluminum alloy matrix squeezed, causing plastic deformation in the direction of weak restrictions and concentrates stress between the interface of aluminum alloy matrix and SiC particles. Furthermore, when the stress exceeds the interfacial limit strength, there can be the phenomena of interfacial debonding. Furthermore, the large tensile stress will also lead to interfacial debonding, as same as the mechanism of scale phenomenon in $2 \mathrm{~A} 12 \mathrm{Al}$.

The phenomena of microcracks, $\mathrm{SiC}$ particle breakage and Al-matrix tearing can be seen from Fig. 8g and $\mathbf{h}$. With the interaction between abrasive particle and material, the large tensile stress behind the abrasive particle will lead to micro-crack initiation and Al-matrix tearing. According to indentation fracture mechanics, if the normal stress in contact-position of $\mathrm{SiC}$ particles exceeds the fracture strength, it will cause median and lateral cracks. With the movement of abrasive particle, the horizontal crack extends to the surface and causes the breakage of Sic particles.

The phenomena of $\mathrm{SiC}$ particles protruding and pulling out can be seen from the Fig. 8i and $\mathbf{j}$. With the movement of abrasive particle, if the interfacial strength of upper half of the $\mathrm{SiC}$ particles much larger than the bottom half one, it will cause $\mathrm{SiC}$ particles pulling out and lead to pits on the surface. Furthermore, if the pulling out $\mathrm{SiC}$ particles are pressed into $\mathrm{Al}$ matrix by abrasive particle again, it may cause protruding of sic particles. In addition, when the tensile stress is very large, the serious interface debonding will cause the protruding of $\mathrm{SiC}$ particles under the $\mathrm{Al}$ matrix as well, as shown in Fig. 8i.

The phenomenon of $\mathrm{Al}$ matrix covering can be seen in Fig. 8k and $\mathbf{l}$. That is because the extrusion of Al-matrix between the $\mathrm{SiC}$ particles produces secondary shear deformation under the action of abrasive particles being very easy to cover the SiC particles in the direction of cutting. From Fig. 81, it can be seen that the phenomenon of Al-matrix covering is especially serious and this is because the high volume fraction of $\mathrm{SiC}$ particles make the deformation of Al-matrix be hindered and the excessive shear stress make the phenomenon of Al-matrix tearing be more serious. There are many pits and cracks in the cladding, as shown in Fig. $\mathbf{8 m}$, causing the weak bonding strength and making the $\mathrm{SiC}$ particles easy to break off. After cleaning the $\mathrm{SiCp} / \mathrm{Al}$ composites with ultrasonic washer for 10 minutes, most of the surface claddings shown in Fig. 8n are cleared, showing the broken particles and cladding fracture surface, as shown in Fig. 8m and $\mathbf{l}$. Thus, it can be seen that the cladding formed by plastic deformation of Al-matrix in the cutting of $\mathrm{SiCp} / \mathrm{Al}$ composites process is also an important defects influencing the surface quality.

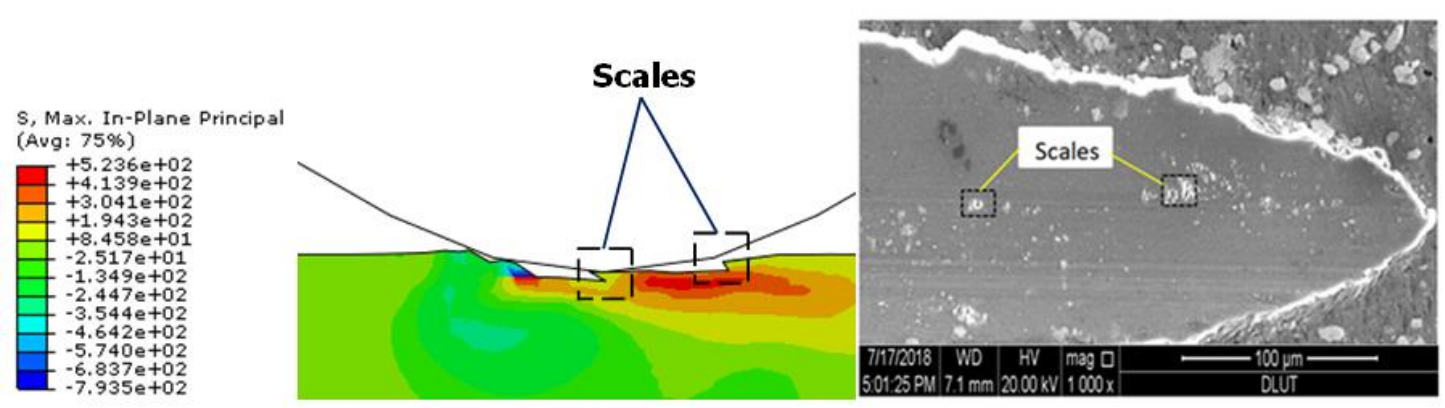

(a)

(b) 
S, Max. In-Plane Principal (Avg: 75\%)

$+4.588 \mathrm{e}+02$
$+3.663 \mathrm{e}+02$
$+2.738 \mathrm{e}+02$
$+1.814 \mathrm{e}+02$
$+8.890 \mathrm{e}+01$
$-3.572 \mathrm{e}+00$
$-9.604 \mathrm{e}+01$
$-1.885 \mathrm{e}+02$
$-2.810 \mathrm{e}+02$
$-3.735 \mathrm{e}+02$
$-4.659 \mathrm{e}+02$
$-5.584 \mathrm{e}+02$
$-6.509 e+02$

Large tensile stress before appearance of scale

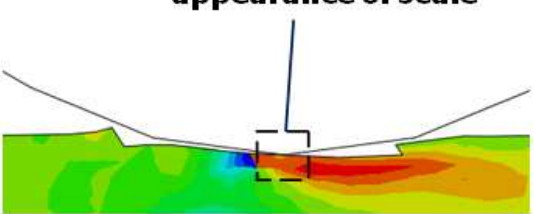

(c)

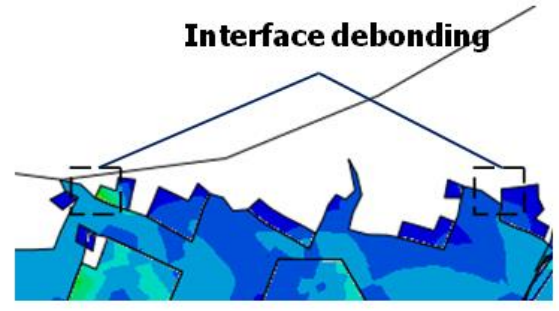

(e)
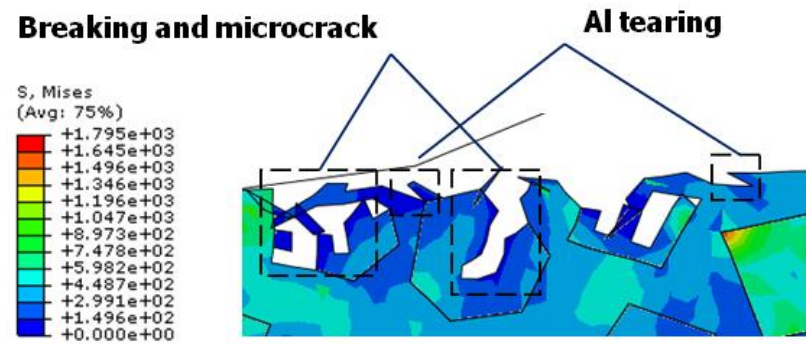

(g)

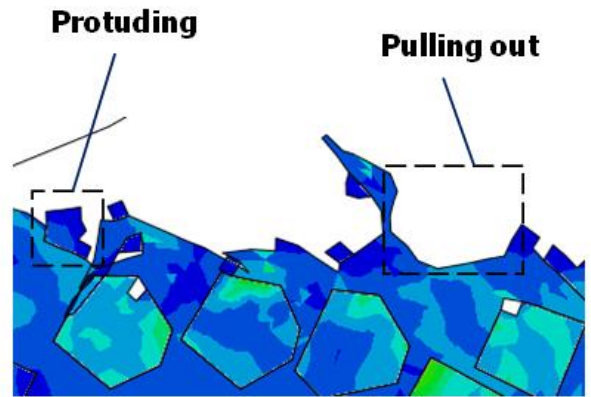

(i)

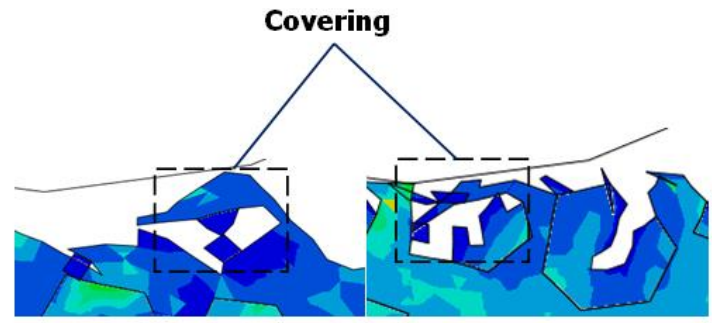

(k)
Scale appearing because of the

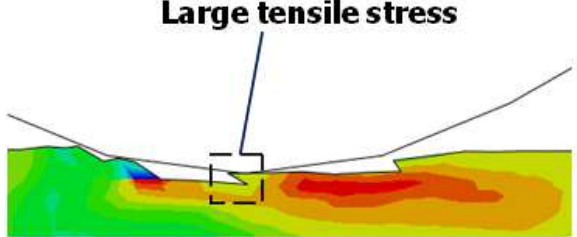

(d)

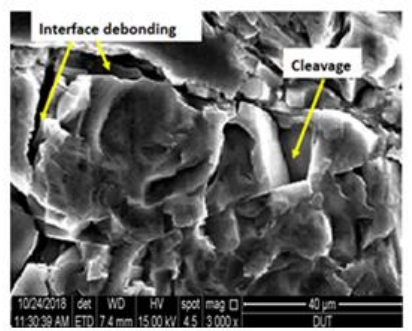

(f)

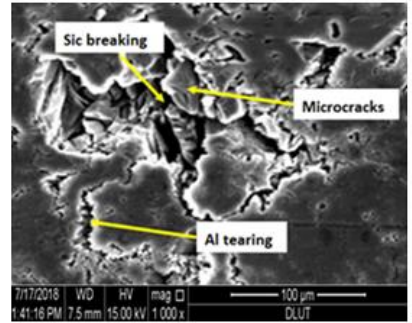

(h)

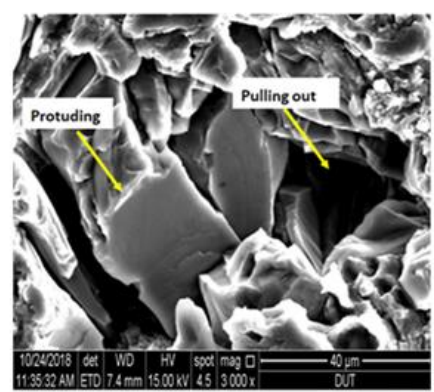

(j)

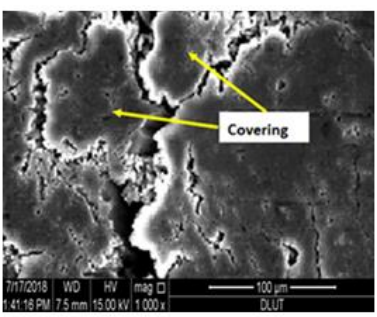

(I) 


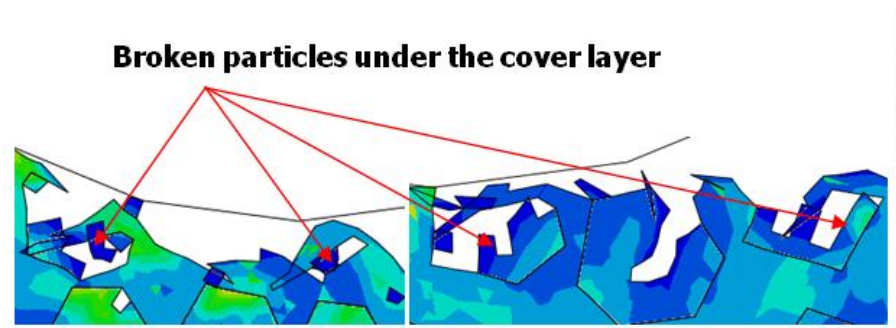

(m)

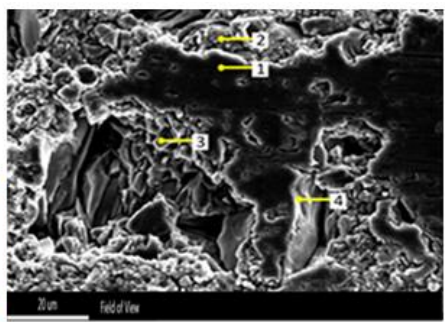

(n)

Fig. 8 Removal models of $2 \mathrm{~A} 12 \mathrm{Al}$, silicon carbide and $65 \% \mathrm{SiCp} / \mathrm{Al}$ composites by simulation and experiment: a-d 2A12 Al, e,f silicon carbide, g-n 65\% SiCp/Al composites

The different positions tagged in the Fig. 8n are analyzed by energy dispersive spectroscopy (EDS) and the major elements are identified, as shown in Fig. 9. It can be seen that the main elements of position tagged number 1 is $\mathrm{Al}$. The position tagged number 2 has the highest amount of $\mathrm{Al}$ and the next is silicon. The major elements of position tagged number 3 and 4 are silicon. Thus, the energy spectrum analysis results show that bellowing the cladding is broken $\mathrm{SiC}$ particles and the cladding consists of Al-matrix and clastic $\mathrm{SiC}$ particles within it, verifying the inference of preceding part of the text.
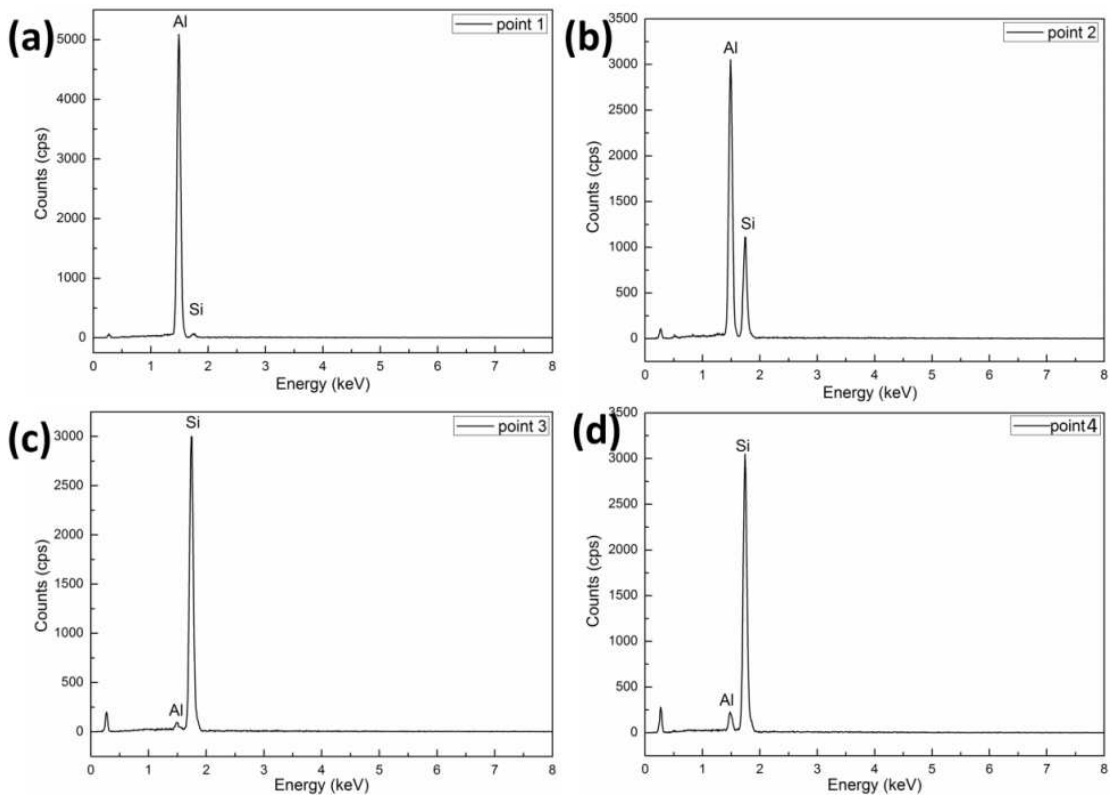

Fig. 9 the result of energy spectrum analysis on cover layer

\section{Conclusions}

In this paper, the single point cutting simulation and experiments were conducted for high-volume fraction $\mathrm{SiCp} / \mathrm{Al}$ composites and $\mathrm{Al}$ alloy. The surface topography was observed, and the surface formation characteristics of $65 \% \mathrm{SiCp} / \mathrm{Al}$ composites were analyzed. Good agreement was found between the experimental and calculated results. The following conclusions can be drawn:

1) The removal characteristics of $\mathrm{SiCp} / \mathrm{Al}$ composites are different from the $\mathrm{Al}$ alloy materials. In the cutting process of $\mathrm{SiCp} / \mathrm{Al}$ composites, there are plastic deformation, ploughing and cumulating of $\mathrm{Al}$ alloy, and 
slippage, detachment and crushing of $\mathrm{SiC}$ particles.

2) The high-volume $\mathrm{SiC}$ particles increase the brittleness and cause the defects like interfacial debonding, al tearing, protruding, and pulling out, crushing, part crushing, and so on. These defects make the profile fluctuate widely. Thus, it lowers the surface quality and profile dimensional accuracy of $\mathrm{SiCp} / \mathrm{Al}$ composites.

3) With the cutting depth increases, fluctuations of $\mathrm{SiCp} / \mathrm{Al}$ profile becoming larger. The range is zero to $8 \mu \mathrm{m}$ when the cutting depth increased gradually to $20 \mu \mathrm{m}$.

4) There are thin and discrete layers covered on the machined surface. The layers consist of Al-matrix and clastic $\mathrm{SiC}$ particles.

\section{Funding information}

This research was supported financially by National Natural Science Foundation of China (NSFC) (Projects no. 51875079, U1908228 ) and Liaoning province "Xingliao Talents Program" young top talent (Projects no. XLYC1907196).

\section{References:}

[1] Rahman MH, Rashed HM(2014) Characterization of Silicon Carbide Reinforced Aluminum Matrix Composites. Procedia Engineering; 90: 103-109

[2] İzciler M, Muratoglu M(2003) Wear behaviour of $\mathrm{SiC}$ reinforced $2124 \mathrm{Al}$ alloy composite in RWAT system. J Mater Process Tech; 132(1-3): 67-72

[3] Lou HS, Qu SG, Li XQ, Wang B, Kuang TR(2016) Glass coating on SiCp / Al composite mirror for ultra-smooth surface. Int J Adv Manuf Tech; 88(5-8): 1745-1753

[4] Kevorkijan VM(1999) Aluminum composites for automotive applications: a global perspective. Jom-Us 51(11):54-58

[5] Lee HS, Jeon KY, Kim HY, Hong SH(2000) Fabrication process and thermal properties of
$\mathrm{SiCp} / \mathrm{Al}$ metal matrix composites for electronic packaging applications. J MATER SCI 35(24):6231-6236

[6] Cui Y, Wang LF, Ren JY(2008) Multi-functional $\mathrm{SiC} / \mathrm{Al}$ composites for aerospace applications. CHINESE J AERONAUT 21(6):578-584

[7] Zhang H(2013) Experimental Investigation on Ultrasonic Vibration-Assisted Turning of $\mathrm{SiCp} / \mathrm{Al}$ Composites. MATER MANUF PROCESS 28(9): 999-1002

[8] Ahamed AR, Asokan P, Aravindan S, Prakash, MK(2010) Drilling of hybrid $\mathrm{Al}-5 \% \mathrm{SiCp}-5 \% \mathrm{~B} 4 \mathrm{Cp}$ metal matrix composites. INT J ADV MANUF TECH 49(9-12): 871-877

[9] Kadivar MA, Akbari J, Yousefi R, Rahi, A,Nick, MG(2014) Investigating the effects of vibration method on ultrasonic-assisted drilling of $\mathrm{Al} / \mathrm{SiCp}$ metal matrix composites. ROBOT CIM-INT MANUF 30(3): 344-350

[10] Zhou L, Huang S, Xu L, Bai D, Zhao P(2013) Drilling characteristics of $\mathrm{SiCp} / \mathrm{Al}$ composites with electroplated diamond drills. INT J ADV MANUF TECH 69(5-8): 1165-1173

[11] Xiong Y, Wang W, Jiang R, Lin K, Song $\mathrm{G}(2016)$ Surface integrity of milling in-situ TiB2 particle reinforced Al matrix composites. INT J REFRACT MET H 54: 407-416

[12] Wang YF, Liao WH, Y ang K, Teng XY, Chen WQ(2019) Simulation and experimental investigation on the cutting mechanism and surface generation in machining $\mathrm{SiCp} / \mathrm{Al}$ MMCs. INT J ADV MANUF TECH 100(5-8),1393-1404

[13] Liu J, Cheng K, Ding H, Chen S, Zhao L(2016) An Investigation of Surface Defect Formation in Micro Milling the $45 \% \mathrm{SiCp} / \mathrm{Al}$ Composite. Procedia Cirp 45: 211-214

[14] Wu Q, Xu W, Zhang L(2018) A micromechanics analysis of the material removal mechanisms in the cutting of ceramic particle reinforced metal matrix composites. MACH SCI TECHNOL 22(4): 638-651

[15] Xiang DH, Shi ZL, Feng HR, Wu BF, Zhang ZM, Chen YB, Niu XX, Zhao B(2019) Finite 
element analysis of ultrasonic assisted milling of $\mathrm{SiCp} / \mathrm{Al}$ composites. INT J ADV MANUF TECH 105(7-8):3477-3488

[16] Wang YF, Liao WH, Yang K, Chen WQ, Liu TT(2019) Investigation on cutting mechanism of $\mathrm{SiCp} / \mathrm{Al}$ composites in precision turning. INT $\mathbf{J}$ ADV MANUF TECH 100(1-4):963-972

[17] Yan C, Zhang L(1994) Single-point scratching of $6061 \mathrm{Al}$ alloy reinforced by different ceramic particles[J]. Applied Composite Materials 1(6): 431-447

[18] Feng PF, L GQ, Zhang JF(2014) Ultrasonic vibration-assisted scratch characteristics of silicon carbide-reinforced aluminum matrix composites[J]. Ceramics International 40(7): 10817-10823

[19] Zha HT, Feng PF, Zhang JF(2018) Material removal mechanism in rotary ultrasonic machining of high-volume fraction $\mathrm{SiCp} / \mathrm{Al}$ composites[J]. International Journal of Advanced Manufacturing Technology 97(5-8): 2099-2109

[20] Shan HL, Guo RX, Xia HT(2009) Numerical simulation of random distribution model of particle reinforced composites $[\mathrm{J}]$ Science and Technology and Engineering 9(10) 2724-2727.

[21] Zhu Y, Kishawy HA(2005) Influence of alumina particles on the mechanics of machining metal matrix composites, Int. J. Mach. Tools Manuf. 45 389-398.

[22] Pramanik A, Zhang LC, Arsecularatne JA(2007) An FEM investigation into the behavior of metal matrix composites: Tool-particle interaction during orthogonal cutting. INT J MACH TOOL MANU 47(10): 1497-1506

[23] Dandekar CR, Shin YC(2009) Multi-step 3-D finite element modeling of subsurface damage in machining particulate reinforced metal matrix composites. COMPOS PART A-APPL S 40(8): 1231-1239

[24] Fathipour M, Zoghipour P, Tarighi J, Yousefi $R(2012)$ Investigation of reinforced sic particles percentage on machining force of metal matrix composite.Mod Appl Sci 6(8): p9
[25] Fathipour M, Hamedi M, Yousefi R(2013) Numerical and experimental analysis of machining of $\mathrm{Al}(20 \mathrm{vol} \% \mathrm{SiC})$ composite by the use of ABAQUS software. MATERIALWISS WERKS 44(1): 14-20

[26] $\mathrm{Li}(2006)$ Experimental study on the constitutive relationship of 2A12 aluminum alloy. Harbin Institute of Technology

[27] Zhou L, Huang ST, Wang D, Yu XL(2011) Finite element and experimental studies of the cutting process of $\mathrm{Si} \mathrm{Cp} / \mathrm{Al}$ composites with PCD tools. INT J ADV MANUF TECH 52(5-8): 619-626

[28] Zhang W, Wei G, Xiao XK(2013) Constitutive relation and failure model of 2A12 aluminum alloy. Acta Armamentarii 34(3):276-282

[29] Liu J, Bai YL, Xu CY(2014) Evaluation of ductile fracture models in finite element simulation of metal cutting processes. J MANUF SCI E-T ASME 136(1): 011010

[30] Zhou L, Cui C, Zhang PF, Ma ZY(2016) Finite element and experimental analysis of machinability during machining of high-volume fraction $\mathrm{SiCp} / \mathrm{Al}$ composites. INT $\mathrm{J} \mathrm{ADV}$ MANUF TECH 91(5-8):1935-1944

[31] Hibbitt, Karlsson, Sorensen(2001) ABAQUS/Explicit: User's Manual, Hibbitt, Karlsson and Sorensen Incorporated

[32] Hibbitt, Karlsson, Sorensen(2006) Abaqus/Explicit Theory and User Manuals. Version 6.6.1.

[33] Kan Y, Liu ZG, Zhang SH,Zhang LW, Cheng M, Song HW(2014) Microstructure-Based Numerical Simulation of the Tensile Behavior of SiC/Al Composites. J MATER ENG PERFORM 23(3):1069-1076

[34] Zhou L, Wang Y, Ma ZY, Yu XL(2014) Finite element and experimental studies of the formation mechanism of edge defects during machining of $\mathrm{Si} \mathrm{Cp} / \mathrm{Al}$ composites. INT J MACH TOOL MANU 84: 9-16 


\section{Figures}

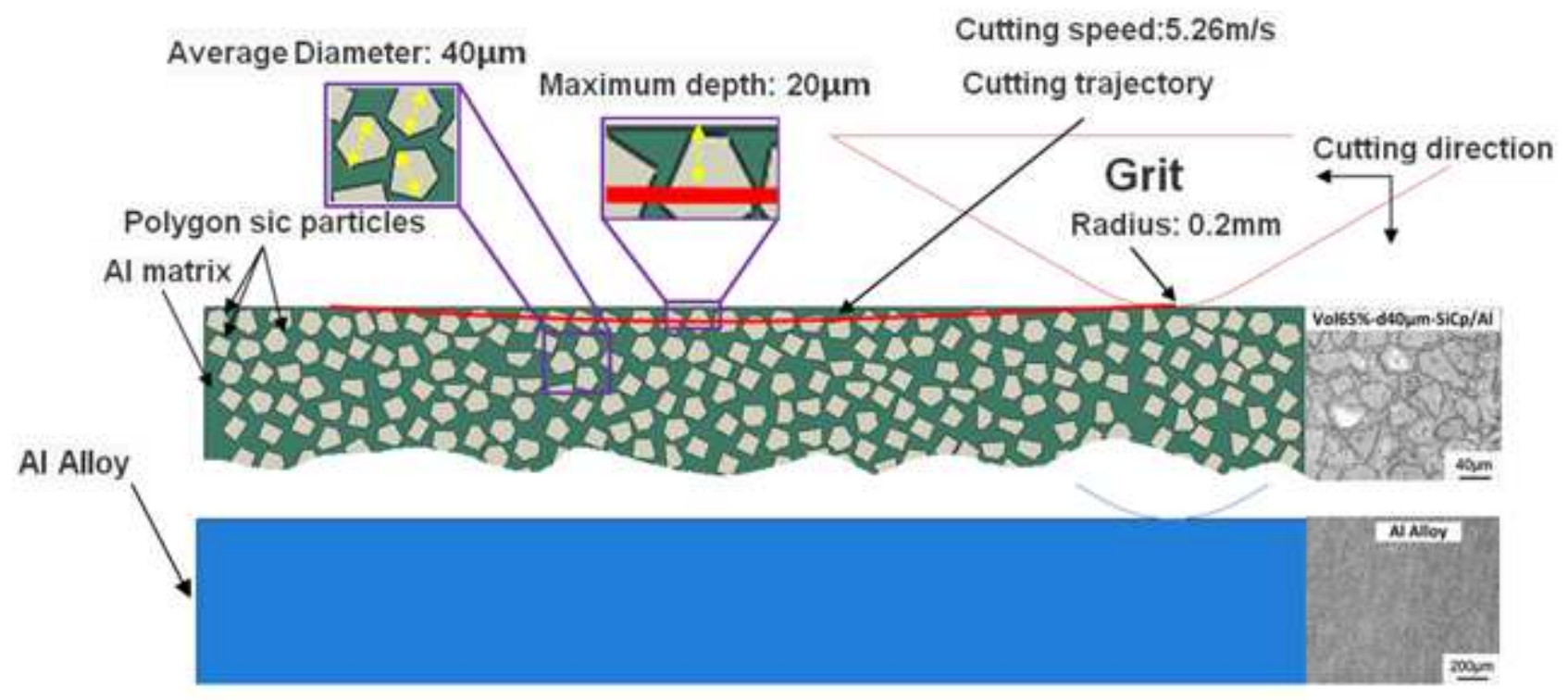

Figure 1

Finite element model of single point cutting of $65 \% \mathrm{SiCp} / \mathrm{Al}$ composites and $2 \mathrm{~A} 12$ aluminum alloy

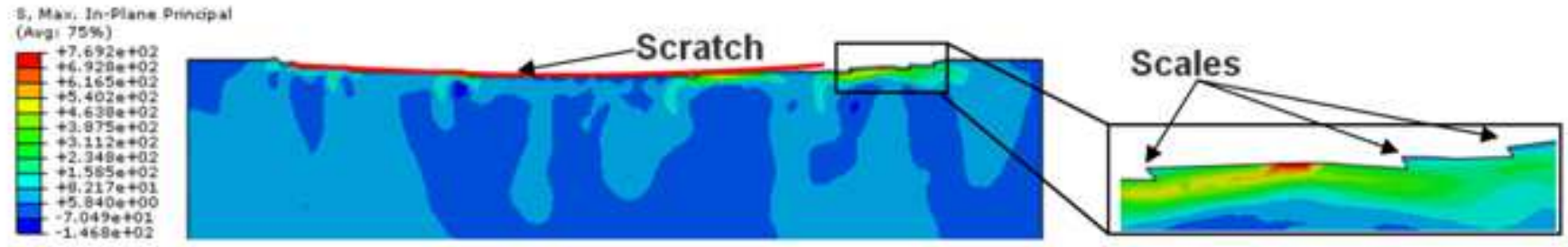

Figure 2

Removal models of $2 \mathrm{~A} 12$ aluminum alloy materials

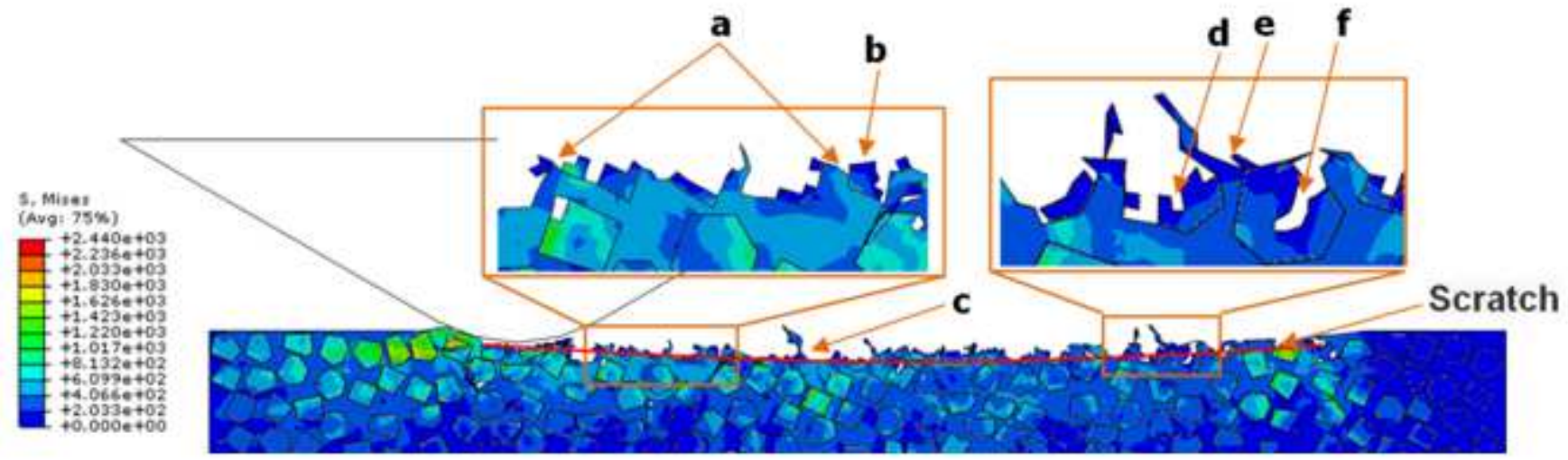

Figure 3 
Removal models of $65 \%$ SiCp/Al composites

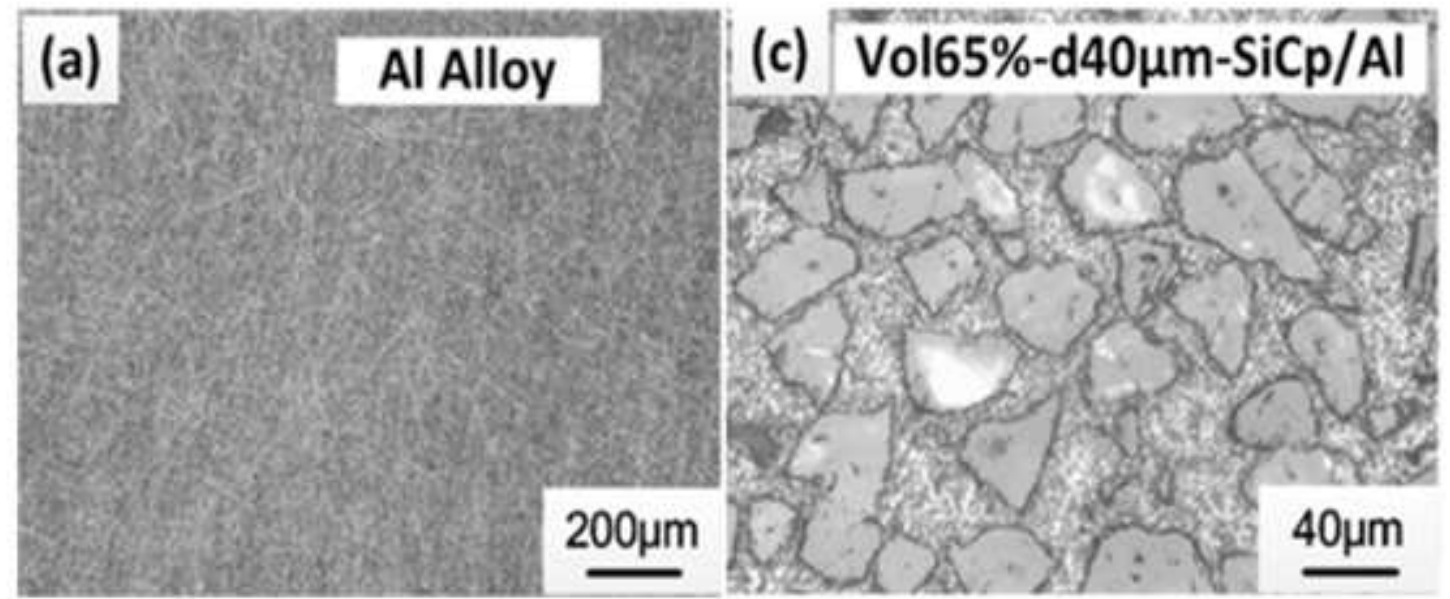

Figure 4

Surface topography of test pieces after pretreatment
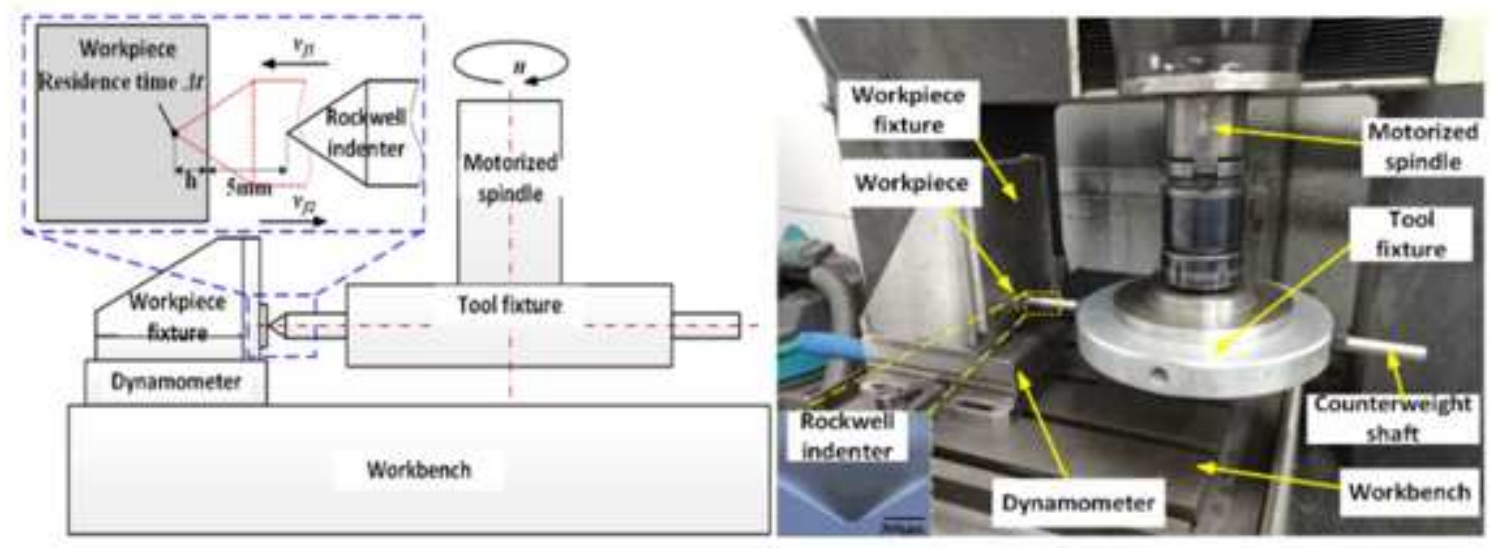

Figure 5

The method of dicing test and testing apparatus

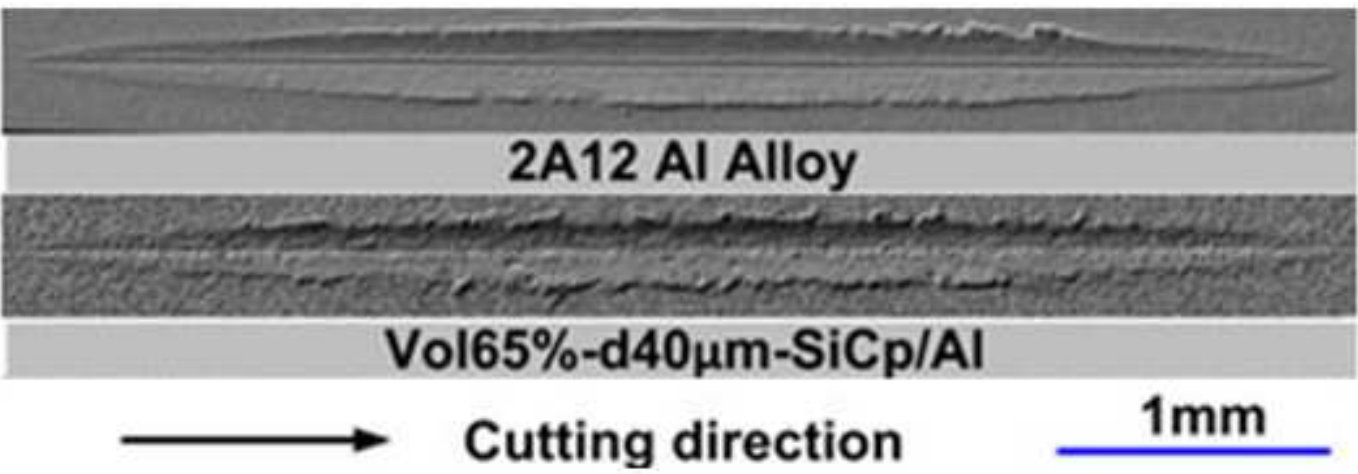

Figure 6 
The overall appearance of three materials after dicing

(a)
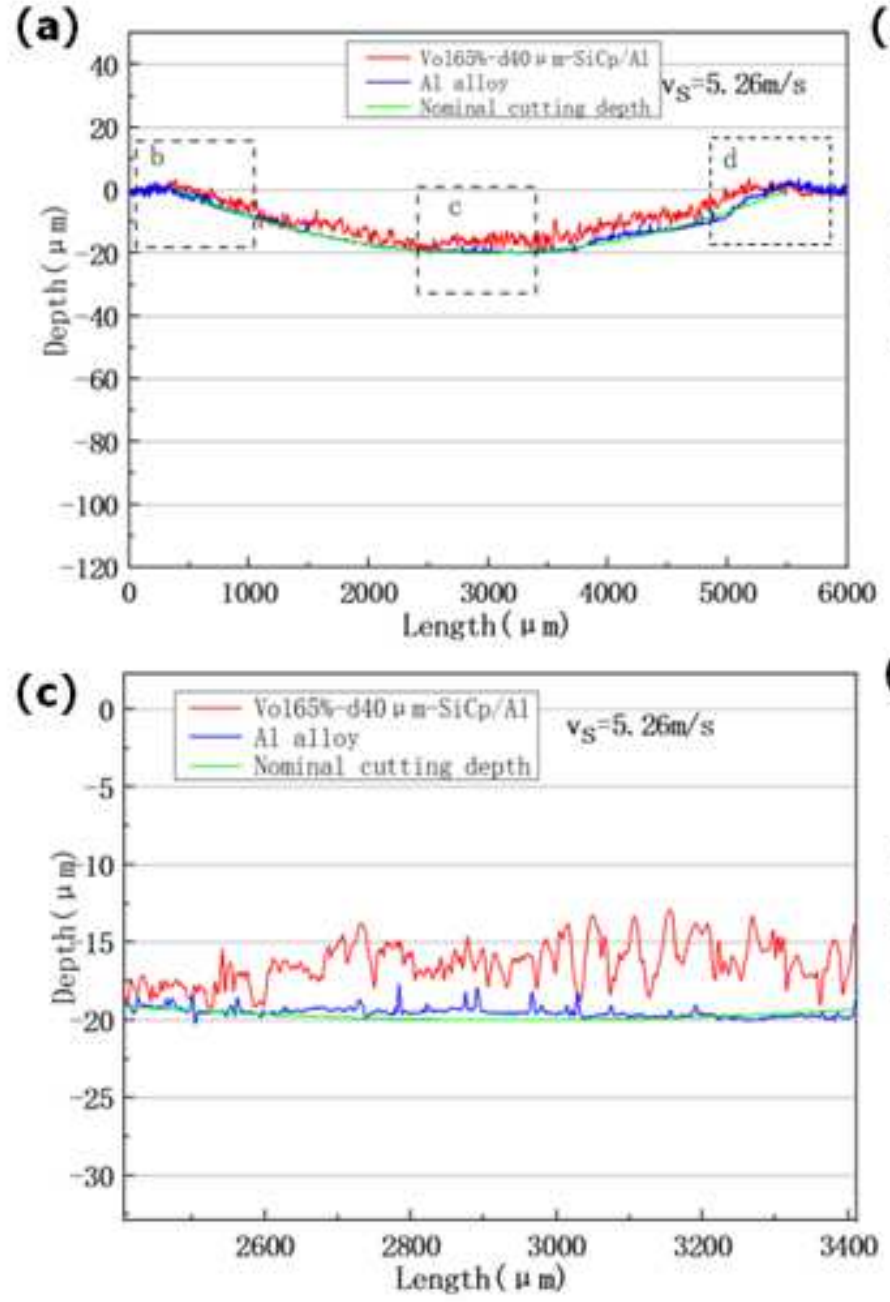

(b)

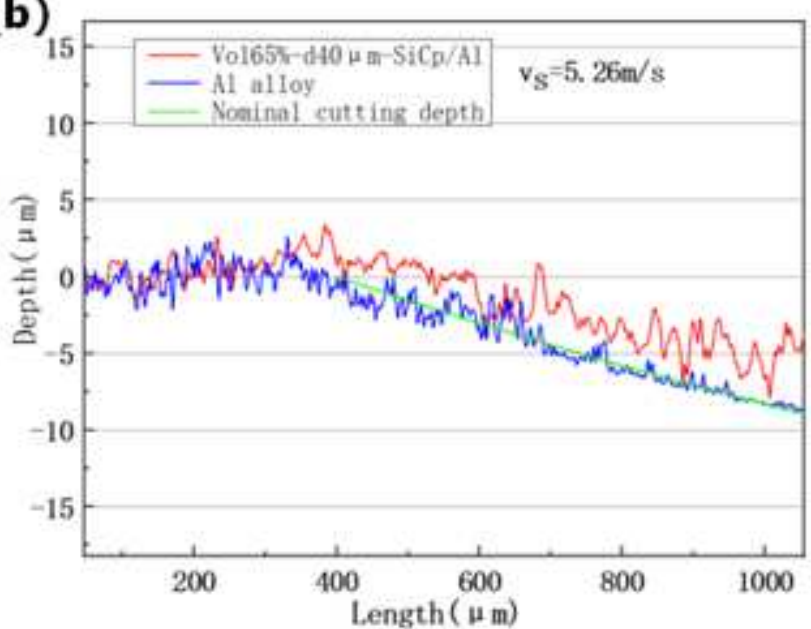

(d)

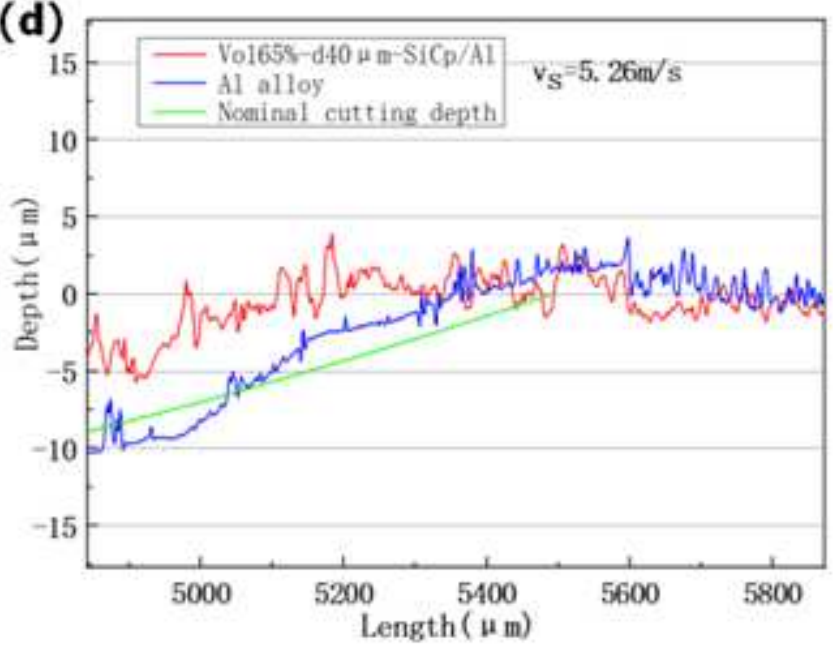

\section{Figure 7}

The scratch profile dimensions of three materials after dicing 


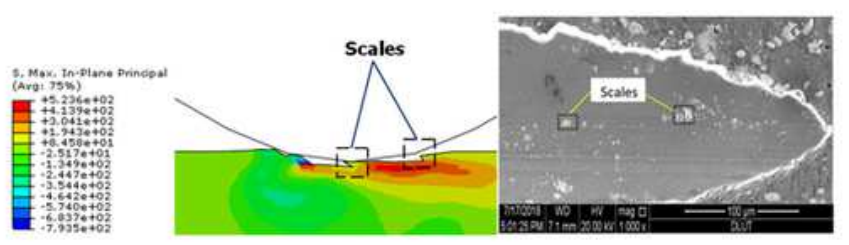

(a)

(b)

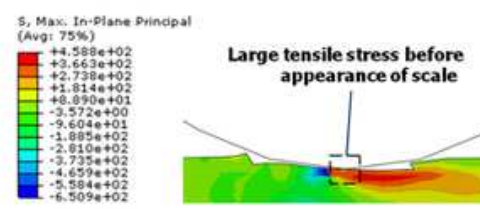

(c)

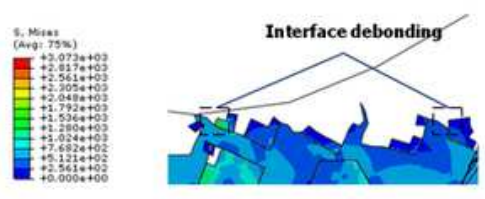

(e)

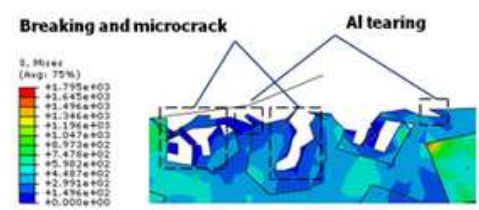

(g)

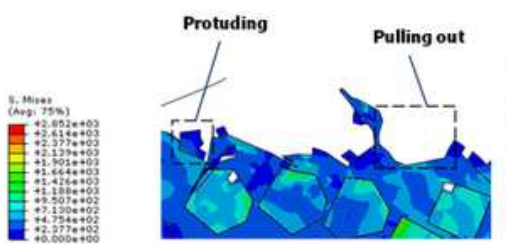

(i)

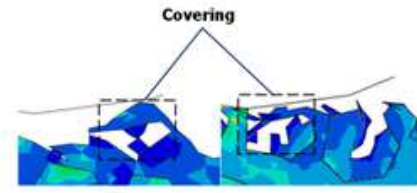

(k)

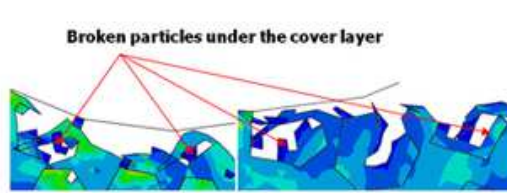

(m)

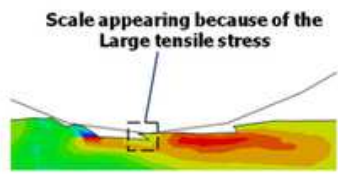

(d)

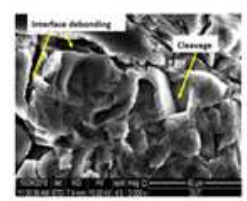

(f)

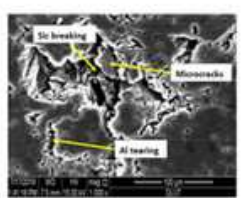

(h)

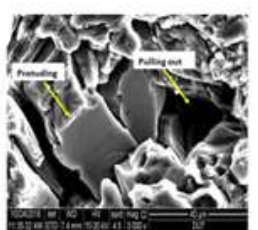

(j)

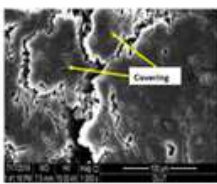

(I)

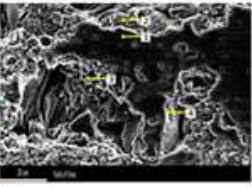

(n)

\section{Figure 8}

Removal models of $2 \mathrm{~A} 12 \mathrm{Al}$, silicon carbide and $65 \% \mathrm{SiCp} / \mathrm{Al}$ composites by simulation and experiment: a-d 2A12 Al, e,f silicon carbide, g-n 65\% SiCp/Al composites 

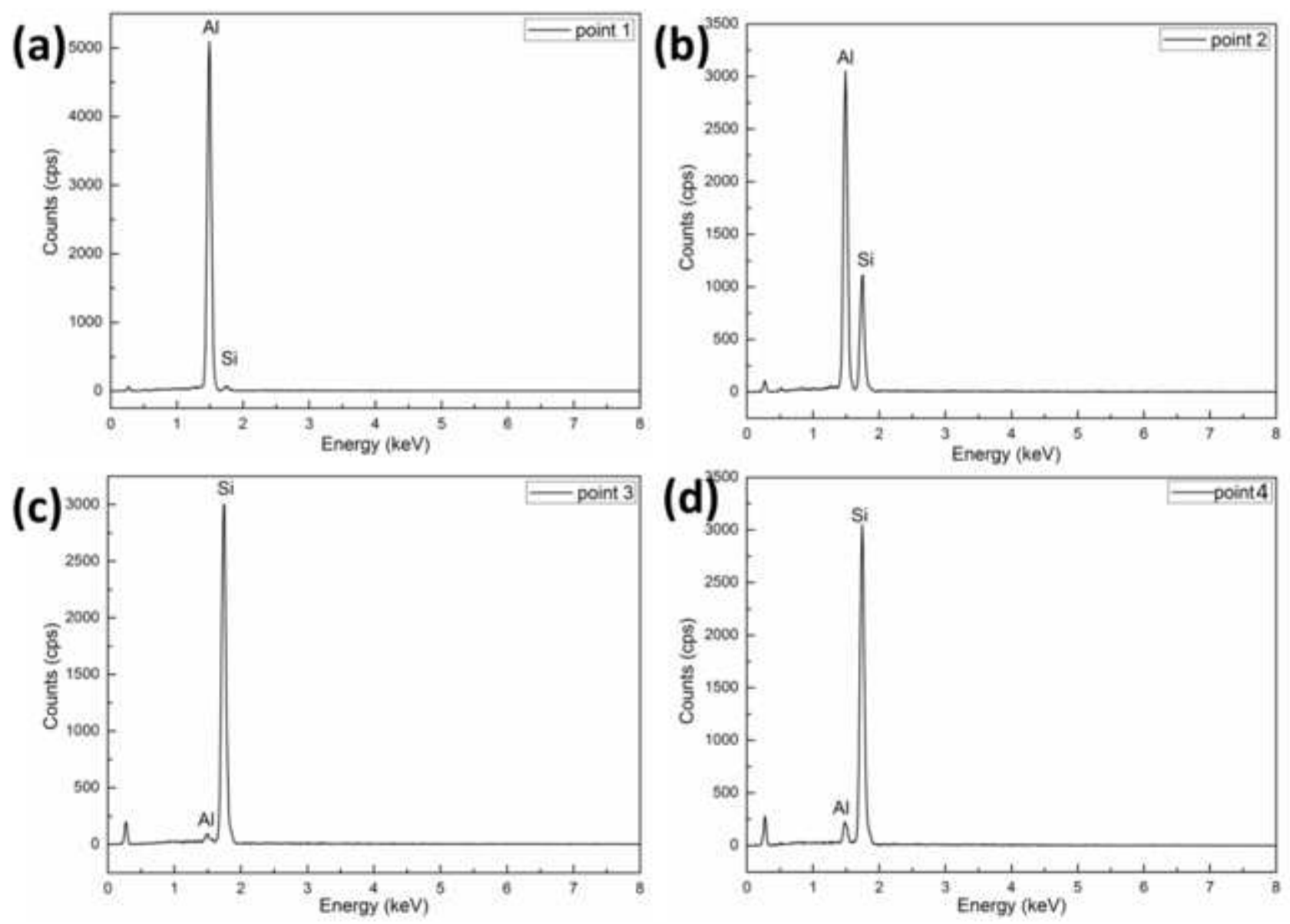

Figure 9

the result of energy spectrum analysis on cover layer 